\title{
ANALISIS TINGKAT BAHAYA BEKERJA DI KETINGGIAN DI AREA UNLOADER PT DERMAGA PERKASAPRATAMA BALIKPAPAN
}

\author{
Isradi Zainal $^{1}$, Dea Monica ${ }^{2}$, Noeryanto ${ }^{3}$ \\ Program Studi Keselamatan dan Kesehatan Kerja, \\ Fakultas Vokasi, Universitas Balikpapan, \\ Email : isradizainal@yahoo.com
}

\begin{abstract}
ABSTRAK
Tujuan dari penelitian ini adalah untuk menganalisis dan mengetahui tingkat bahaya yang dihadapi pekerja pada kegiatan bekerja di ketinggian dan upaya pengendalian keselamatan dan kesehatan kerja di PT Dermaga Perkasapratama. Penelitian ini termasuk penelitian kualitatif. Data primer dikumpulkan dengan observasi lapangan dan wawancara serta data sekunder yang diperoleh dari perusahaan. Narasumber dalam penelitian ini adalah 5 (lima) orang pekerja dan 1 mekanik unloader Data yang diperoleh dianalisis secara deskriptif dengan menggunakan tabel HIRAC (Hazard Identification and Risk Assessment Control) dan dibandingkan dengan standard dan teori yang ada. Metode yang digunakan penulis dalam melakukan identifikasi bahaya dan penilaian risiko mengacu pada aturan IBPR PT. Dermaga Perkasapratama. Hasil penelitian menunjukan terdapat 2(dua) kegiatan bahaya yang teridentifikasi.Hasil penilaian risiko terdapat 21(dua puluh satu). Dan 12 (dua belas) bahaya dengan risiko sedang dan 10 bahaya dengan risiko rendah. Jenis pengendalian bahaya yang sudah dilakukan meliputi teknis, administrasi dan penyediaan alat pelindung diri. Manajemen perusahaan disarankan untuk meninjau kembali dokumen IBPR perusahaan dengan meninjau langsung lokasi, alat kerja, dan cara kerja sehingga potensi bahaya yang mungkin ada pada suatu kegiatan tersebut dapat teridentifikasi dan di tentukan tindakan pengendaliannya.
\end{abstract}

Kata Kunci: Bahaya, Bekerja di Ketinggian.

\section{ABSTRACT}

The purpose of this study is to analyze and find out the level of danger faced by workers in working activities at heights and efforts to control occupational safety and health at PT Dermaga Perkasapratama. This research is a qualitative research. This research is a qualitative research. Primary data were collected by field observations and interviews and secondary data obtained from the company. Resource persons in this study were 5 (five) workers and 1 mechanical unloader Data obtained were analyzed descriptively using HIRAC (Hazard Identification and Risk Assessment Control) tables and compared with existing standards and theories. The method used by the author in identifying hazards and risk assessments refers to the IBPR rules of PT. Perkasapratama Pier. The results showed that there were 2 (two) hazard activities identified. The results of the risk assessment were 21 (twenty one). And 12 (twelve) hazards with moderate risk and 10 hazards with low risk. Types of hazard control that have been carried out include technical, administrative 
and the supply of personal protective equipment. Company management is advised to review the company's $I B P R$ documents by directly reviewing the location, work tools, and ways of working so that the potential hazards that may be present in an activity can be identified and its control measures determined.

Keywords: Hazard, working at Height, HIRAC.

\section{PENDAHULUAN}

Di Seoul (Korea Selatan) sebuah Crane yang tengah digunakan untuk menyelesaikan sebuah proyek kontruksi mendadak roboh. Akibat kejadian tersebut sedikitnya dua orang tewas dan tiga lainnya terluka. Ketika kejadian di ketahui terdapat lima orang pekerja kontruksi yang tengah berada dalam crane tersebut .

Akibat robohnya crane tersebut kelima pekerja itu jatuh dari ketinggian 55 meter. Kejadian ini terjadi di wilayah Namyangju, Timur laut Kota Seoul. Dua dari lima pekerja tewas ditempat kejadian. Ketiga pekerja lainnya dilarikan kerumah sakit dalam kondisi keritis. (Okenews 23/05/2017).

Badan Penyelenggara Jaminan Sosial (BPJS) Ketenagakerjaan mencatat angka kecelakaan kerja di Indonesia cenderung terus meningkat. Sebanyak 123 ribu kasus kecelakaan kerja tercatat sepanjang 2017. Berdasarkan Tribun News Tiga orang peke rja tewas seketika dalam kecelakaan kerja di proyek pembangunan Harris dan POP Hotel Solo, Jumat pagi. Setelah gondola yang mereka pakai naik ke lantai 10 ternyata talinya putus saat berada di lantai tujuh. Akibatnya 3 orang jatuh dari ketinggian sekitar 28 meter, karena tiap lantai tingginya empat meter. kecelakaan kerja itu terjadi akibat kelalaian pihak pekerja.

Beberapa masalah yang teridentifikasi adalah: (1) PT Dermaga Perkasapratama merupakan salah satu perusahaan industri batubara dan menunjang kemajuan teknologi dan indsutri yang bergerak di bidang pengimportan berupa terminal batubara. maka dari itu peneliti berusaha untuk melakukan kajian mengenai analisa tingkat bahaya dan penilaian risiko terhadap pekerjaan diatas kentinggian serta upaya pengendalian keselamatan dan kesehatan kerja di PT Dermaga Perkasapratama .(2) Kemungkinan risk assessment yang dilakukan kurang tepat dan lengkap.

\section{METODE PENELITIAN}

Penelitian ini termasuk penelitian deskriptif kualitatif. Data primer dikumpulkan dengan observasi lapangan dan wawancara serta data sekunder yang diperoleh dari perusahaan. Narasumber 
dalam penelitian ini terdiri dari 5 orang pekerja unloader dan 1 mekanik unloader. Waktu penelitian di laksanakan pada tahun 2019 di Tanjung Batu Kota Balikpapan.

Data primer dikumpulkan dengan melakukan observasi lapangan yakni dengan mengikuti kegiatan diarea unloader kemudian melakukan identifikasi bahaya yang ada pada setiap proses kegiatan yang merupakan job desk dari pekerja. Selain itu diperlukan data sekunder yang diperoleh dari perusahaan berupa dokumen-dokumen yang relevan seperti SOP, dan dokumen IBPR perusahaan.

Setelah bahaya diidentifikasi lalu dilakukan penilaian bahaya dengan teknik semi kualitatif dengan mengkombinasikan antara nilai probability, frekuensi dan severity untuk mengetahui tingkat risiko sehingga dapat dilakukan upaya pengendalian sesuai bahaya yang ada didasari dengan urutan hirarki pengendalian yakni eliminasi, subtitusi, rekayasa teknis, administrasi, dan alat pelindung diri.

Data yang diperoleh dianalisis secara deskriptif dengan menggunakan tabel dan dibandingkan dengan standard, peraturan dan teori yang berhubungan dengan kegiatan K3 di ketinggian seperti peraturan Menteri Ketenagakerjaan Nomor Per 09/Men/2016. Metode identifikasi bahaya dan penilaian risiko (IBPR) yang digunakan mengacu pada IBPR milik PT Dermaga Perkasapratama.

\section{HASIL DAN PEMBAHASAN}

PT Dermaga Perkasapratama adalah pelabuhan dan terminal batubara di Teluk Tebang Kelurahan Kariangau Kecamatan Balikpapan Barat Kota Balikpapan.

Sistem pengapalan batubara yang dilakukan sekarang adalah dengan menggunakan transportasi tongkang atau ponton dari lokasi. Dengan kesulitan yang dialami saat pemuatan batubara serta kurangnya prasarana pemuatan menjadikan Kalimantan yang memiliki kandungan sumber daya alam yang cukup besar menjadi kurang diharapkan dalam bersaing di pasaran dunia walaupun harga batubara di Kalimantan lebih murah dibandingkan Negara lain seperti Australia.

Proses identifikasi tingkat bahaya dan penilaian risiko para kegiatan bekerja diketinggian di PT Dermaga Perkasapratama ini, peneliti hanya berfokus mengidentifikasi tingkat bahaya dan penilaian risiko pada rangkaian kegiatan, serta dengan memperhatikan 4M1E (Man, Material, Method, Machine, and Environment) dalam mengidentifikasi bahaya dan risiko yang ada sesuai keadaan dilapangan. 
Peneliti menemukan 2 (dua) kegiatan tersebut peneliti mengidntifikasi tingkat bahaya berdasarkan hasil observasi dan wawancara yang kemudian di analisa menggunakan metode HIRAC yang dimana Risk Matrix tersebut mengacu milik perusahaan.

Kegiatan pertama yaitu naik unloader Berdasarkan hasil observasi dan wawancara dengan pekerja potensi bahaya yang teridentifikasi pada kegiatan naik tangga unloader ada 5 (lima) potensi bahaya dan 5 (lima) risiko yang mana dari 5 (lima) potensi bahaya tersebut peneliti menemukan 3 (tiga) bahaya baru yakni bahaya ruang terbatas, ceceran oli, dan tangga curam. bahaya tersebut tidak terdapat pada dokumen hirac perusahaan. Kegiatan kedua yaitu pengoperasian unloader Berdasarkan hasil observasi dan wawancara dengan pekerja, potensi bahaya yang telah teridentifikasi pada kegiatan pengoperasiaan unloader ada 16 (enam belas) potensi bahaya dimana dari 16 (enam belas) potensi bahaya tersebut meliputi swing bucket, petir, sling putus, kebisingan, ceceran batu bara, tersengat arus listrik, tertimpa batu bara, getaran, limbah logam, kelelahan, ceceran grease dan oli, polusi udara, cuaca buruk, jam kerja operasional, kebocoran freon, arus pendek ,itu lah yang terdapat pada dokumen HIRAC Perusahaan.
Dengan ini peniliti menemukan 1 (satu) bahaya baru yaitu jam kerja operasional, yang tidak terdapat pada Risk Matrix perusahaan.

\section{HASIL TINGKAT BAHAYA DAN RISIKO KATEGORI MEDIUM}

Berdasarkan hasil dari penilaian HIRAC didapatkan tingkat bahaya dengan kategori Medium sebesar 55\%, adapun tingkat bahaya dengan kategori Medium meliputi unskil person, polusi udara, swing bucket, sling putus, tersengat arus listrik,getaran, limbah logam, kelelahan, ceceran grease dan oli, ceceran batu bara, cuaca buruk.

\section{HASIL TINGKAT BAHAYA DAN RISIKO KATEGORI LOW}

Berdasarkan hasil dari penilaian HIRAC didapatkan tingkat bahaya dengan kategori Low sebesar 45\%, adapun tingkat bahaya dengan kategori Low meliputi tangga curam, ruang terbatas, ceceran oli, petir, tertimpa batu bara, polusi udara, jam kerja operasional, kebocoran freon, arus pendek.

\section{HASIL AKHIR PENILAIAN TINGKAT BAHAYA DAN RISIKO}

Setiap bahaya yang ada pada kegiatan unloader dapat dilihat tingkat bahayanya lalu 
peneliti menilai tingkat bahaya dan risiko tersebut menggunakan metode risk matrix.

Pada kegiatan unloader terdapat 2 (dua) kegiatan yang telah teridentifikasi bahaya dan risikonya yang mana pada kegiatan ini terdapat 12 (dua belas) risiko medium dengan presentase sebanyak 55\%, 10 (sepuluh) risiko low dengan presentase sebanyak $45 \%$ dan tidak di temukan risiko dengan tingkat risiko high atau signifikan.

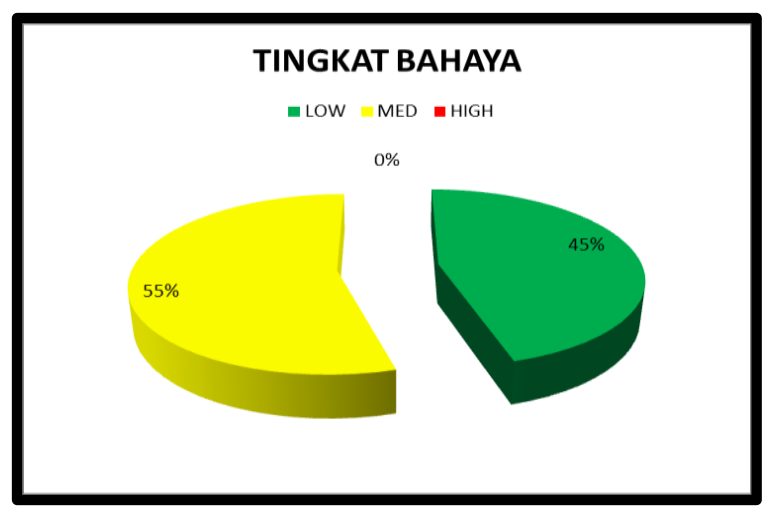

Gambar : Diagram tingkat bahaya

\section{HASIL WAWANCARA}

Berdasarkan hasil wawancara dengan 6 informan yang terlibat dalam pekerjaan unloader ini rata-rata informan mengetahui jobsdesk dari masing-masing pekerjaannya. Informan juga mengetahui seluruh tahapan dari pekerjaan unloader yang ada.

Informan mengetahui dan memahami bahaya serta risiko terkait pekerjaan diketinggian ini. Bahaya jatuh dari tangga menjadi bahaya yang memiliki risiko tinggi menurut para informan. Berdasarkan hasil wawancara peneliti menarik kesimpulan para informan tidak mengetahui adanya menejemen risiko terkait pekerjaan mereka dan juga tidak pernah terlibat langsung dalam menyusun dokumen identifikasi bahaya dan penilaian risiko (IBPR) perusahaan.

\section{KESIMPULAN}

Bahaya yang teridentifikasi pada kegiatan unloader di PT Dermaga Perkasapratama, teridentifikasi 21 (dua puluh satu) bahaya yang meliputi tangga curam, ruang terbatas, ceceran oli, unskil person, polusi udara, swing bucket, petir, sling putus, kebisingan, ceceran batu bara, tersengat arus listrik, tertimpa batu bara, getaran, limbah logam, kelelahan, ceceran grease dan oli, polusi udara, cuaca buruk, jam kerja operasional, kebocoran freon, arus pendek. Tingkat bahaya dari potensi bahaya yang ada didapatkan 10 (sepuluh) kategori risiko rendah (low) dengan persentase sebesar $45 \%, 12$ (dua belas) kategori risiko sedang (medium) dengan persentase sebesar 55\% dan tingkat bahaya dengan kategori risiko tinggi (high) tidak ditemukan.

Hal ini dikarenakan pada saat melakukan identifikasi bahaya dan penilaian risiko pada proses kegiatan unloader sudah 
terdapat beberapa pengendalian yang ada dan telah dilakukan oleh PT Dermaga Perkasapratama. Tingkat bahaya dari bahaya tangga curam dengan risiko terjatuh . Dari 21 (dua pulu satu) bahaya yang ada peneliti menemukan 4 (empat) bahaya baru yang tidak terdapat pada dokumen IBPR peruahaan.

Upaya pengendalian risko yang dilakukan pada proses unloader di PT Dermaga Perkasapratama terdapat 10 upaya pengendalian yang meliputi 3 jenis atau metode pengendalianyakni melalui metode rekayasa teknik, administratif dan pengunaan APD yang disesuaikan dengan bahaya yng muncul disetiap proses kerja di unloader.

\section{SARAN}

Berdasarkan hasil yang ada perlu adanya revisi terkait dokumen identifikasi bahaya penilaian risiko (IBPR) perusahaan. Karena, banyak terdapat potensi bahaya yang tidak terassessment. Usahakan dalam melakukan identifikasi bahaya penilaian risiko (IBPR) harus mengikuti diagram alir menejemen risiko yang diadopsi dan melihat serta menilai seluruh potensi bahaya dari segala aspek (4M1E) sehingga potensi bahaya yang mungkin ada pada suatu kegiatan tersebut dapat teridentifikasi dan ditentukan tindakan selanjutnya.
SOP memang merupakan kontrol administrasi. Namun kontrol tidak hanya SOP, maka dari itu perlu dilakukan IBPR untuk mengetahui kontrol apa saja yang bisa mendampingi SOP tersebut. Mengingat konsep dari Identifikasi Bahaya Penilaian Risiko (IBPR) ini adalah mengidentifikasi dan menghitung seluruh potensi bahaya baik itu yang pernah terjadi atau tidak, seluruh aspek bahaya dan risiko harus tetap di identifikasi dan dihitung agar dapat menjadi langkah preventif (pencegahan).

\section{DAFTAR PUSTAKA}

All About Safety Id. 2016. Bekerja Pada Ketinggian.ttps://allaboutsafetyid.wo rdpress.com/2016/12/30/bekerjapada-ketinggian.

Anak Katiga. 2018. Jenis- jenis Bahaya. https://anakkatiga.blogspot.com/2018 /03/jenis-jenis-bahaya-hazard-dalamk3.html.

Bird, dan Germain. 1990. Jenis-jenis Kecelakaan.https://www.sekolahpen didikan.com/2017/12/pengertiankecelakaan-kerja-beserta.html\#

Blogger. 2015. Mengidentifikasi Bahaya. http://vatsunk.blogspot.com/2016/03/ mengidentifikasi-bahayahazard.html.

\section{Floating Cargo Cranes Liebherr} https://www.liebherr.com/shared/me dia/maritime-cranes/downloads-andbrochures/fts/fts_downloads_brochur 
es/liebherr-floating-cranes-cbg-300350.pdf

International Standard. 2009. ISO 31000:

Risk Management-Principles and Guidelines. Geneva: ISO.

Keputusan Mentri Tenaga kerja Republik Indonesia Nomor: Kep. 463/MEN/1993 Tentang Kesehatan Kerja.

Media Project. 2013. Teori-Teori Kecelakaan Kerja.https://projectmedias.blogspot. com/2013/09/teori-teori-kecelakaankerja.html

My Media. 2016. Tindakan Tidak Aman, Kondisi Tidak Aman.http://mymedia0511.blogspot.c om/2016/01/tindakan-tidak-amankondisi-tidak aman. htmlokenews. 2017.

news.okezone.com. 2017. Crane Roboh, Lima Pekerja Kontruksi di Korsel Jatuh dari Ketinggian Puluhan Meter. https://news.okezone.com/read/2017/ 05/23/18/1697452/crane-roboh-limapekerja-kontruksi-di-korsel-jatuhdari-ketinggian-puluhan-meter

Peraturan Mentri Ketenaga Kerjaan Republik Indonesia Nomor: Per 09/Men/2016 Tentang Keselamatan Kerja Pekerjaan Pada Ketinggian.

Peraturan Pemerintah Republik Indonesia Nomor: 50 Tahun 012 Pasal 13 Ayat 3 Tentang Penerapan Sistem Manajemen Keselamatan dan Kesehatan Kerja.

Peraturan Menteri Ketenaga kerjaan Republik Indonesia Nomor: Per 03/Men/1998. Tentang Tata Cara
Pelaporan dan Pemeriksaan Kecelakaan.

PT DPP. Intruksi Kerja Operasional Unloader. ISO 14001. Nomor Dokumen: DPP-SOP-OPR-002.

Prasko Tujuh Belas.2013. Klasifikasi Kecelakaan Kerja. http://prasko17. blogspot.com/2013/03/klasifikasikecelakaan-kerja.html.

Republik Indonesia, 1970. Undang-Undang Republik Indonesia No. 1 Tahun 1970 tentang Keselamatan Kerja. Lembaran Negara Republik Indonesia Tahun 1970 Nomor 1. Sekretariat Negara. Jakarta

Republik Indonesia, 1970. Undang-Undang Republik Indonesia No. 1 Tahun 1970 Bab III Pasal 3. Tentang Keselamatan Kerja dan Syarat-Syarat Keselamatan Kerja. Sekretariat Negara. Jakarta.

Safety Net Staff. 2017. Penyebab Terjadinya Kecelakaan Kerja. http://safetynet.asia/penyebabterjadinya-kecelakaan-kerja/.

Seputar Com Sepengetahuan. 2017. Pengertian Manajemen Risiko Menurut Para Ahli. http://www.sepengetahuan.com/2017 /11/pengertian-manajemen-risikomenurut-paraahli.html\#15Darmawi _2014.

Silalahi, Bennet N.B dan Rumondang B. Silalahi. 1995. Manajemen Keselamatan dan Kesehatan Kerja. Jakarta: PT Pustaka Binaman Pressindo.

Soehatman Ramli, 2009. Sistem Manajemen Keselamatan dan Kesehatan Kerja 
OHSAS 18001. PT Dian Rakyat. Jakarta.

Sugiyono. 2014. Metode Penelitian Pendidikan Pendekatan Kuantitatif, Kualitatif, dan $R$ \& D., Alfabeta. Bandung.

Suma'mur.2009. Pengertian Kecelakaan Kerja. Jurnal Hasil Riset. https:// www.ejurnal.com/2014/11/pengertia n-kecelakaan-kerja.html.

Triwibowo, dan Puhandani, ME. 2013. Kesehatan Lingkungan dan K3. Nuha Medika. Yogyakarta.

Tribun.News. 2017. Tiga pekerja proyek pembangunan hotel tewas terjatuh dari ketinggian 28 meter. Jawa Tengah.

Dewi Agustina. http://www.tribunnews.com /regional/2017/04/21/tiga-pekerjaproyek-pembangunan-hotel-tewasterjatuh-dari-ketinggian-28-meter.

Yusuf Zalaya, 2012. Implementasi Prosedur Bekerja Diketinggian Di PT BBS Indonesia (WTC 2 Project) Tahun 2012. Skripsi. Fakultas Kesehatan Masyarakat, Universitas Indonesia : Depok.

Wordpress, 2018. K3 Bekerja Diketinggian. http://agtry.com/k3-bekerjadi-ketinggian/ 